\title{
Comparison of the Effects of Isotonic and Hypertonic Sodium Bicarbonate Solutions on Acidemic Calves Experimentally Induced by Ammonium Chloride Administration
}

\author{
Shigehiro IWABUCHI ${ }^{1)}$, Kazuyuki SUZUKI ${ }^{1,2)}$, Izumi ABE ${ }^{1)}$ and Ryuji ASANO ${ }^{2)}$ \\ ${ }^{1)}$ Central Research Laboratories, Nippon Zenyaku Kogyo Co., Ltd., 1-1 Aza Tairanoue, Sasagawa, Asakamachi, Koriyama, Fukushima \\ 963-0196 and ${ }^{2)}$ Department of Veterinary Medicine, College of Bioresource Sciences, Nihon University, 1866 Kameino, Fujisawa, \\ Kanagawa 252-8510, Japan
}

(Received 28 January 2003/Accepted 25 August 2003)

ABSTRACT. The objectives of this study were to evaluate and compare the effects of intravenously (IV) administered infusion of isotonic solution (ISB) or hypertonic sodium bicarbonate solution (HSB) on acid-base equilibrium and the plasma osmolarity in acidemic calves experimentally induced by $5 \mathrm{M}-\mathrm{NH}_{4} \mathrm{Cl}$, IV infusion $(1.0 \mathrm{~m} / \mathrm{kg}$, over $1 \mathrm{hr})$. The ISB and HSB infusion induced progressive and significant increases in their $\mathrm{HCO}_{3}{ }^{-}$and $\mathrm{BE}$ levels that persisted throughout the period of fluid administration. The plasma osmolarity in the ISB groups was significantly decreased. The plasma osmolarity in the HSB group was significantly higher than in the calves in the other groups $(\mathrm{p}<0.05)$. ISB solution might be safe and effective for treating and reviving conscious calves from experimentally induced metabolic acidosis.

KEY WORDS: calf, metabolic acidosis, sodium bicarbonate solution.

J. Vet. Med. Sci. 65(12): 1369-1371, 2003

Calves suffering from severe diarrhea become dehydrated with metabolic acidosis, losing water, electrolytes and bicarbonate. To correct those problems, sodium bicarbonate is specifically effective in cases of severe metabolic acidosis because it has a rapid effect when given IV [5-8, $10,11,17]$. But, rapid administration or overdose with $7.0 \%$ hypertonic $\mathrm{NaHCO}_{3}$ solution (HSB) has been associated with the development of extracellular fluid hyperosmolarity, cerebrospinal fluid acidosis and intracranial hemorrhage [5]. If a $1.35 \%$ isotonic $\mathrm{NaHCO}_{3}$ solution (ISB) can restore the rehydration and acid-base equilibrium without the risk of hyperosmolarity, it can be confidently used to treat dehydrated calves with severe metabolic acidosis. The purpose of this study was to evaluate and compare the effects of IV infusion of ISB solution and IV infusion of an equivalent intensity of HSB on the biological parameters of venous $\mathrm{HCO}_{3}^{-}, \mathrm{BE}$ and plasma osmolarity in conscious calves with experimentally induced metabolic acidosis.

All procedures were conducted under the National Research Council Guidelines for the Care and Use of Laboratory Animals (National Acadamy Press, 1996).

Eighteen healthy Holstein calves weighing of $56.3 \pm 9.6$ $\mathrm{kg}$ were used in this study. All the calves received $1.0 \mathrm{~m} / \mathrm{kg}$ of $5 \mathrm{M}-\mathrm{NH} 4 \mathrm{Cl}$ (Conclyte-A, Yoshitomi Seiyaku Co., Ltd., Osaka, Japan) via a right jugular catheter over a period of 1 $\mathrm{hr}$ to induce metabolic acidosis. The $5 \mathrm{M}-\mathrm{NH}_{4} \mathrm{Cl}$ solution has been used clinically to correct metabolic alkalosis in humans. The administration of $\mathrm{NH}_{4} \mathrm{Cl}$ is equivalent to administration of $\mathrm{HCl}$, because the $\mathrm{NH}_{4}{ }^{+}$is converted to $\mathrm{H}^{+}$ and urea in the liver [3]. The $\mathrm{NH}_{4} \mathrm{Cl}$ infusion induced renal tubular acidosis. This tubular acidosis is characterized by hyperchloremic metabolic acidosis caused by either decreases in $\mathrm{HCO}_{3}{ }^{-}$reabsorption or defective acid excretion at the normal rate of glomerular filtration.

After completion of this infusion, six calves were randomly assigned to each of the following groups: the control group (no bicarbonate solution given), the ISB group (IV infusion of ISB) or the HSB group (IV infusion of HSB). Fluid infusion was started at 10 min after completion of 5M$\mathrm{NH}_{4} \mathrm{Cl}$ infusion. Regardless of the base deficit in an acidemic calf, the total amount of base required to normalize the blood $\mathrm{pH}$ can be calculated with the acceptable formula $[2,9,12,18]$. In general, sodium bicarbonate should be used for the treatment of severe acidemia $(\mathrm{BE} \leq-10 \mathrm{mM})$. It has been recommended that the first half of the calculated dose of sodium bicarbonate solution should be administered rapidly [2]. Furthermore, a previous study demonstrated that infusion volume of ISB was $10.2 \mathrm{ml} / \mathrm{kg}$, enough to correct the first half of the $10 \mathrm{mEq} / l$ the of base deficit in acidemic calves [16]. In this study, therefore, the calves in the ISB and HSB groups were given an IV infusion of $5 \mathrm{mM}$ ISB $(10.0 \mathrm{~m} / / \mathrm{kg})$ or HSB $(1.9 \mathrm{~m} / / \mathrm{kg})$ via the left jugular catheter over a $15 \mathrm{~min}$ period, with an infusion pump (PRS25, Nikkiso Co., Tokyo, Japan).

Venous blood samples were collected immediately before (pre-acidification) and after acidification (post-acidification), and at 0 (baseline), 5, 10, 15, 30, 45, 60, 90, 120, 150 and $180 \mathrm{~min}$ after the start of infusion of either ISB or HSB. The time between post-acidification and baseline was 5 min. Venous blood samples were analyzed for $\mathrm{pH}$ and other blood gas concentrations with an automatic gas analyzer at $37^{\circ} \mathrm{C}$ (Model 248, Bayer Medical Co., Tokyo, Japan) and for the hemoglobin concentration and hematocrit value (MEK-6248, Nihon Koden Co., Tokyo, Japan). The $\mathrm{pH}$ and gas values were automatically corrected to reflect each calf's rectal temperature. The changes in the rPV were 
calculated from the hemoglobin concentrations and hematocrit values, by using accepted formulas $[4,14]$. The plasmas were separated after being centrifuged from other blood specimens, and were stored at $-20^{\circ} \mathrm{C}$ until the measurement of plasma osmolarity (One-Ten Osmometer, Fiske Co., Norwood, MA, U.S.A.).

The data are expressed as the means \pm the standard deviation. The effects of acidification pre- and post-acidification were analyzed with the paired $t$-test. Data were also examined by repeated-measures analysis of variance. The variables included in the model were time, fluid infusion, and interaction of time and fluid infusion. The significance level was at $P<0.05$.

The pre-acidification values for the venous $\mathrm{pH}, \mathrm{HCO}_{3}{ }^{-}$, base excess (BE) and total carbon dioxide $\left(\mathrm{ctCO}_{2}\right)$ concentrations were $7.427 \pm 0.019,28.2 \pm 2.1 \mathrm{mM}, 3.1 \pm 1.7 \mathrm{mM}$ and $29.1 \pm 2.7 \mathrm{mM}$, respectively. The acidification induced significant decreases in the venous $\mathrm{pH}(7.181 \pm 0.094$, $\mathrm{p}<0.001)$, the $\mathrm{HCO}_{3}^{-}(11.9 \pm 2.1 \mathrm{mM}, \mathrm{p}<0.001)$, the $\mathrm{BE}$ $(-15.7 \pm 2.8 \mathrm{mM}, \mathrm{p}<0.001)$ and the $\mathrm{ctCO}_{2}(12.9 \pm 2.2 \mathrm{mM}$, $\mathrm{p}<0.001)$ at completion of the $5 \mathrm{M}-\mathrm{NH} 4 \mathrm{Cl}$ IV infusion. All the calves were hypovolemic after the $5 \mathrm{M}-\mathrm{NH}_{4} \mathrm{Cl}$ infusion, as verified by a decrease in their rPV. The mean decrease in the rPV was $25.2 \pm 9.9 \%$.

The infusion of ISB and HSB induced progressive and significant increases in $\mathrm{pH}$ persisted throughout the experimental period ( $\mathrm{p}<0.001$, Fig. 1). The $\mathrm{pH}$, and $\mathrm{BE}, \mathrm{HCO}_{3}^{-}$ and $\mathrm{ctCO}_{2}$ concentrations in the control group remained constant during the infusion period (Figs. 1, 2). In the ISB and $\mathrm{HSB}$ groups, the $\mathrm{HCO}_{3}{ }^{-}, \mathrm{BE}$ and $\mathrm{ctCO}_{2}$ levels after the infusion progressively and significantly increased until the completion of the fluid infusion $(\mathrm{p}<0.001)$, but no significant differences were detected in the concentrations between the ISB and HSB treatment groups. The administration of $\mathrm{HCO}^{-}$, ISB or HSB to calves with severe metabolic acidosis can effectively improve their acid-base disorder. No significant differences were observed in the values of acid-base equilibrium parameters between calves in the ISB and HSB groups.

Sequential changes in the rPV and plasma osmolarity were monitored in calves with metabolic acidosis (Fig. 3). The rPV values in the control and HSB groups increased slightly and then restored to the respective pre-treatment values at $120 \mathrm{~min}$ after the start of fluid infusion. In contrast, the rPV in the ISB group increased significantly, exceeded the pre-acidification levels and was significantly greater than that in the other groups $(\mathrm{p}<0.001)$. The $5 \mathrm{M}$ $\mathrm{NH}_{4} \mathrm{Cl}$ infusion significantly increased the plasma osmolarity from the pre-treatment value of $287.8 \pm 4.1$ to a posttreatment value of $310.5 \pm 9.5 \mathrm{mOsmol} / l(\mathrm{p}<0.001)$. The plasma osmolarities in the control and ISB groups were significantly decreased $(\mathrm{p}<0.001)$. The plasma osmolarity in the HSB group was significantly higher than those in the other treatment groups $(\mathrm{p}<0.001)$.

Sodium bicarbonate solution is the alkalizing agent of choice for veterinary practitioner and is most often used as a $7.0 \%$ hypertonic solution that is commercially available in

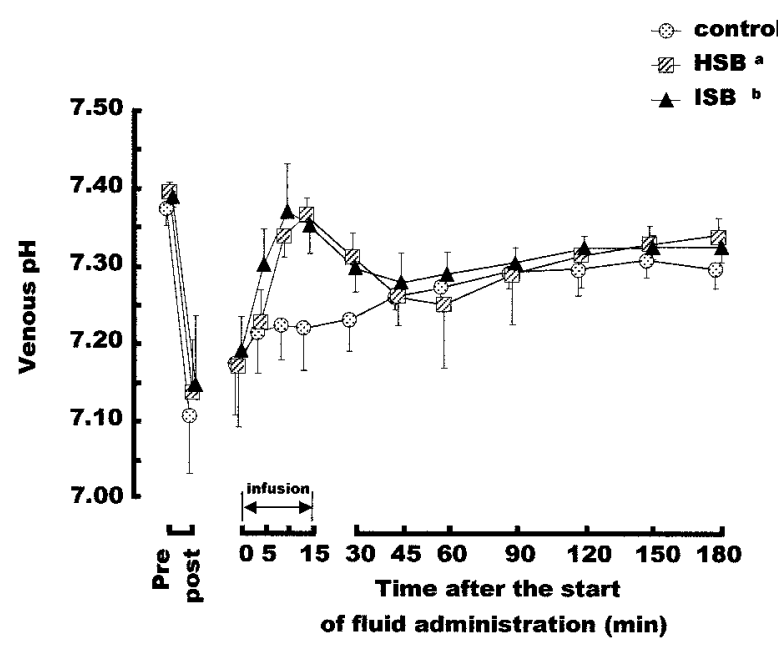

Fig. 1. Graphs depicting the venous $\mathrm{pH}$ in calves with metabolic acidosis given isotonic or hypotonic sodium bicarbonate solution. Control, not given bicarbonate solution: HSB, IV infusion of $7.0 \%$ sodium bicarbonate solutions: ISB, IV infusion of $1.35 \%$ sodium bicarbonate solution. Levels of significance $(\mathrm{p}<0.05)$ are indicated as: $a$, control versus HSB: b, control versus ISB: and c, HSB versus ISB.

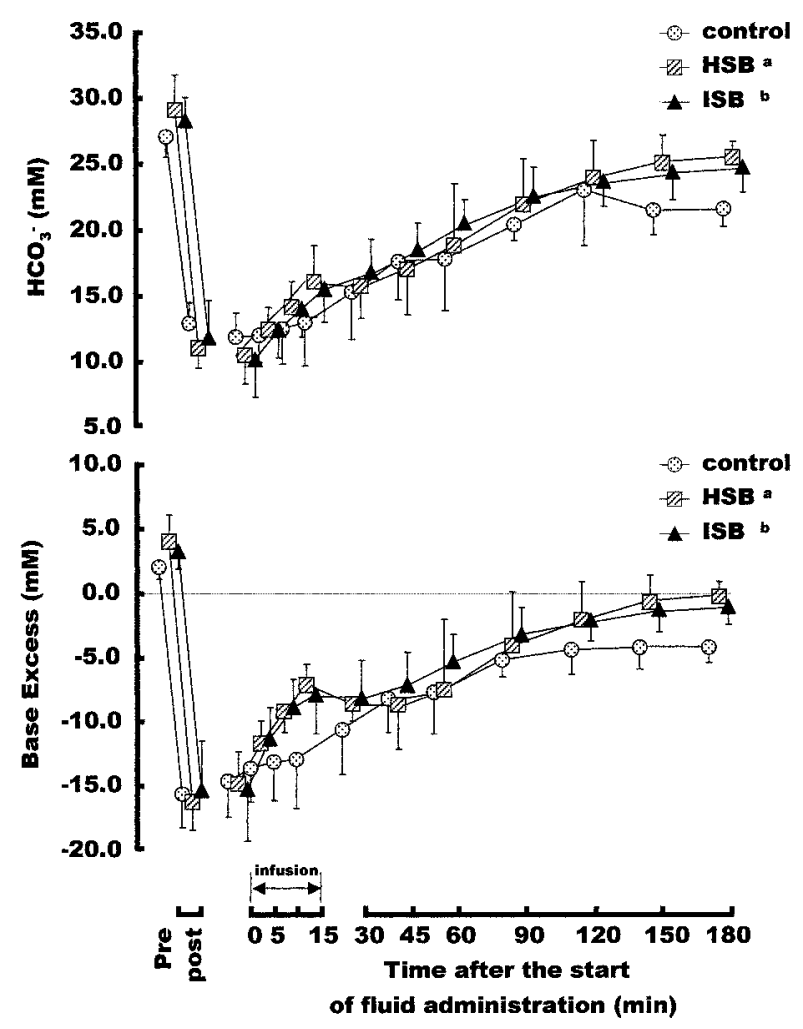

Fig. 2. Graphs depicting the venous ionized bicarbonate $\left(\mathrm{HCO}_{3}^{-}\right)$ and base excess (BE) concentrations in calves with metabolic acidosis given isotonic or hypertonic sodium bicarbonate solution. See Fig. 1 for key. 


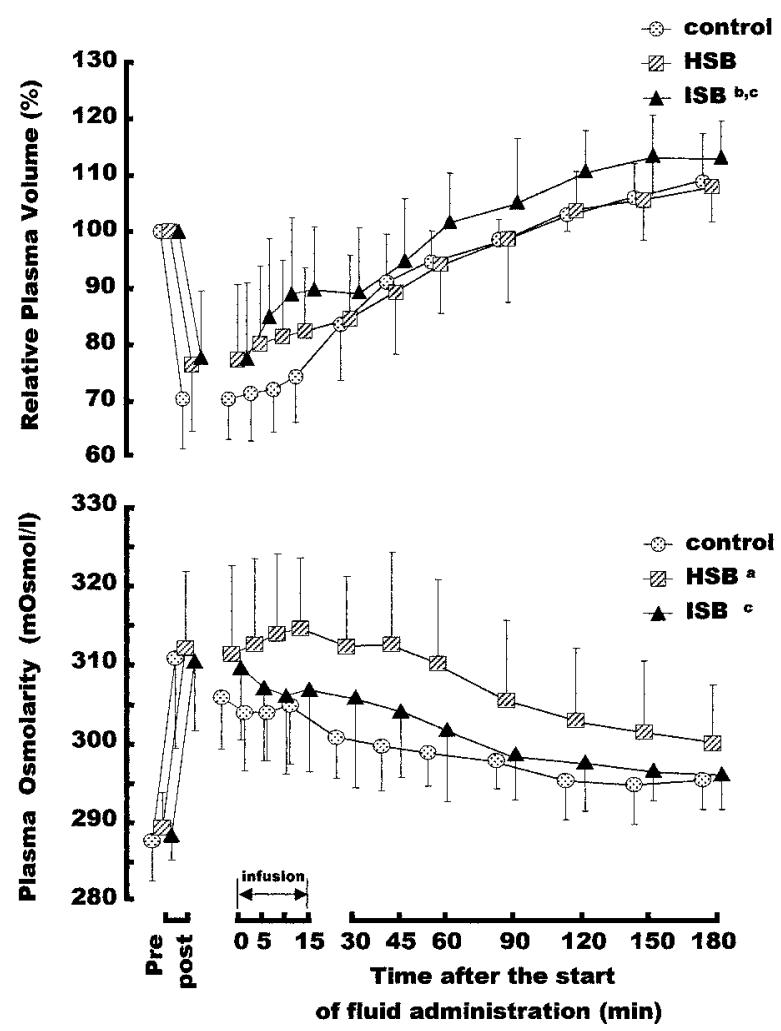

Fig. 3. Graphs depicting the relative plasma volume (rPV) and plasma osmolarity in calves with metabolic acidosis given isotonic or hypertonic sodium bicarbonate solution. See Fig. 1 for key.

Japan. The beneficial restoring effects of hypertonic solutions such as $7.2 \%$ hypertonic saline solution and HSB are primarily due to rapid plasma volume expansion $[1,14,15]$. These responses are produced by an increase in the plasma osmolarity of 30 to $150 \mathrm{mOsmol} / l$ [14]. Nevertheless, rapid administration or an overdose of hypertonic solution has been reported to be associated with extracellular fluid hyperosmolarity, CSF acidosis and intracranial hemorrhage [5]. An abrupt change in the osmolarity can lead to cerebral hemorrhage due to large oscillations in the concentration of electrolytes, and the water and acid-base status [5]. In a previous study [13], IV infusion of 5, 10 and $15 \mathrm{~m} / / \mathrm{kg}$ of ISB over $30 \mathrm{~min}$ did not induce any abnormal clinical signs, and the increases in central venous pressure were less than 1.5 $\mathrm{mmHg}$. In addition, the effects of ISB infusion on respiratory and cardiovascular systems were minimal [13]. In this study, however, the plasma osmolarity in the HSB group was significantly higher than that in the other treatment groups. Therefore, the rapid infusion of ISB may be more beneficial and safe than rapid infusion of HSB, for treatment of calves and correction of their metabolic acidosis.

The findings of this study indicated that ISB could be used to correct severe metabolic acidosis, without significant risk of hyperosomolarity in diarrheic calves. Therefore, the IV infusion of ISB should be evaluated further as a treatment for dehydration and severe metabolic acidemia that develops naturally in calves. Additional research is necessary before definitive recommendations can be made regarding the optimal use for the treatment of this condition.

\section{REFERENCES}

1. Ajito, T., Suzuki, K. and Iwabuchi S. 1999. J. Vet. Med. Sci. 61: 637-641.

2. Berchtold, J. B. 1999. Vet. Clin, North. Am. Food Anim. Pract. 15: 505-531.

3. DiBartola, S. P. 2000. Metabolic acidosis disorder. pp. 211261. In: Fluid Therapy in Small Animal Practice, 2nd ed. (DiBartola, S. P.). WB Saunders Co., Philadelphia.

4. Greenleaf, J. E, Convertino, V. A. and Mangeseth, G. R. 1979. J. Appl. Physiol. 47: 1031-1038.

5. Hartsfield, S. M., Thurmon, J. C. and Benson, G. J. 1981. J. Am. Vet. Med. Assoc. 179: 914-916.

6. Kasari, T. R. and Naylor, J. M. 1984. Can. Vet. J. 25: 394-399.

7. Kasari, T. R. and Naylor, J. M. 1985. J. Am. Vet. Med. Assoc. 187: 392-397.

8. Kasari, T. R. and Naylor, J. M. 1986. Can. J. Vet. Res. 50: 502508.

9. Michell, A. R., Bywater, R. J., Clarke, K. W., Hall, L. W. and Watermann, A. E. 1989. Quantitative aspects of fluid therapy. pp. 104-120. In: Veterinary Fluid Therapy, Blackwell Scientific Publication, London, UK.

10. Naylor, J. M. 1987. Can Vet. J. 28: 168-173.

11. Naylor, J. M. 1989. Can Vet. J. 30: 577-580.

12. Roussel, A. 1999. Vet. Clin. North. Am. Food Anim. Pract. 15: 545-557.

13. Suzuki, K., Abe, I, Iwabuchi, S., Tsumagari, S., Matsumoto, T. and Asano, R. 2002. J. Vet. Med. Sci. 64: 699-703.

14. Suzuki, K., Ajito, T. and Iwabchi, S. 1997. Am. J. Vet. Res. 59: 452-457.

15. Suzuki, K., Ajito, T. and Iwabuchi, S. 1998. J. Vet. Med. Sci. 60: $799-803$

16. Suzuki, K., Kato, T., Tsunoda, G., Iwabuchi, S., Asano, K. and Asano, R. 2002. J. Vet. Med. Sci. 64: 1173-1175.

17. Tremblay, R. R. M. 1990. Vet. Clin. North. Am. Food Anim. Pract. 6: 77-101.

18. Tromp, A. M. 1990. Vet. Clin. North. Am. Food Anim. Pract. 6: 103-110. 